\title{
FACTORS THAT INFLUENCE STUDENTS' DECISION TO DROPOUT OF ONLINE COURSES
}

\author{
Pedro A. Willging \\ Department of Human Resource Education \\ University of Illinois at Urbana-Champaign \\ Champaign, IL 61820 \\ Email: willging@uiuc.edu
}

Scott D. Johnson

Department of Human Resource Education

University of Illinois at Urbana-Champaign

Champaign, IL 61820

Email:sjohnson@uiuc.edu

\begin{abstract}
Although there are many reasons why students dropout of college courses, those reasons may be unique for students who are enrolled in an online program. Issues of isolation, disconnectedness, and technological problems may be factors that influence a student to leave a course. To understand these factors, an online survey was developed to collect data from students who dropped out of an online program. Logistic regression analysis was used to compare various factors between those who persist in the program and those who dropout. The results, based on the dropouts from three cohorts in an online graduate program, show that demographic variables do not predict likelihood of dropping from a program. Instead, the students' reasons for dropping out of an online program are varied and unique to each individual. Recommendations for further study are incorporated in the conclusions.
\end{abstract}

\section{INTRODUCTION}

The landscape of education is changing with the increasing popularity of online instruction. Developments in educational use of computers, software, and distributed networks have led to questions about the effectiveness of this new method of educational delivery and the conditions that make it a successful experience for learners [1,2]. Dropout rate is one measure of the effectiveness of an online program. Program quality can be determined, in part, by calculating student completion rates [3], and these rates tend to be lower for online classes [4]. This suggests that online programs may be less desirable for certain students than the more traditional face-to-face type of instruction.

"While there is now some statistical information available on distance education at higher education institutions in the United States, very few, if any, research surveys have focused on online education" [5]. National estimates on attrition in graduate programs in higher education are not available, in part due to the diversity of the programs and in the difficulty in establishing common metrics that allow valid crossprogram comparisons of program completion and dropout rates [6]. Moreover, since high dropout rates reflect poorly on a program, which can impact program promotion and recruitment efforts, some institutions have registration procedures that mask attrition. For example, at the British Open University, beginning students register on a temporary basis, and, if they withdraw within three months of starting the 
program, their official registration will not show up on the University records [7].

Mostly from anecdotal information, it is estimated that dropout rates for distance education are higher than those for on-campus programs and courses. Some studies roughly estimate that students enrolled in distance education are twice as likely to drop out than on-campus students. For example, Dutton, Dutton, and Perry [8] studied two class sections of an introduction to computer programming course; one was taught on-campus and the other in an online version of the course. Their results revealed substantial differences in the likelihood of students to complete the course. The online students had a $72.2 \%$ completion rate, while $90.3 \%$ of the undergraduates completed their face-to-face course. A study of enrollment and attrition rates for the online MBA program at West Texas A\&M University found that online courses enroll more students than traditional campus courses but they also suffer from higher attrition rates [9]. That study was conducted by analyzing 15 graduate business courses offered during the past three years where the same professor taught both the campus and the Internet courses.

\section{LITERATURE REVIEW}

Two theories provide a comprehensive theoretical framework that might explain why students leave a course. One of these theories is Tinto's Student Integration Model, in which persistence is hypothesized to be related to how well the individual's motivation and academic ability match the institution's academic and social characteristics. This match shapes a person's commitment to completing college and commitment to the institution [10]. The second theory, Bean's Model of Student Departure, predicts persistence based on behavioral intention. These behavioral intentions are shaped by beliefs and attitudes. Student's experiences within the institution, but also factors external to the institution, can affect beliefs, attitudes, and decisions [11]. Noting some gaps in Tinto's theory, a convergence model has been suggested that combines the major propositions embedded in these two theories [12].

The American College Testing (ACT) program collects data about collegiate dropout rates in general. Table 1 shows dropout rate means and standard deviations for freshmen to sophomore year by type of institution. More than 2,500 institutions are included in the compiled data for these 2003 estimates [13].

Table 1: Freshman to Sophomore Year by Type of Institution

\begin{tabular}{llll}
\hline Degree Level & $\mathrm{N}$ & $\begin{array}{l}\text { Dropout Rate } \\
\text { Mean (\%) }\end{array}$ & $\begin{array}{l}\text { Standard } \\
\text { Deviation }\end{array}$ \\
\hline Two-year Public & 729 & 47.2 & 14.6 \\
Two-year Private & 122 & 33.0 & 18.4 \\
BA/BS Public & 84 & 31.8 & 13.4 \\
BA/BS Private & 464 & 29.6 & 16.6 \\
MA Public & 227 & 30.2 & 10.7 \\
MA Private & 506 & 25.7 & 12.0 \\
PhD Public & 214 & 22.7 & 9.4 \\
PhD Private & 184 & 17.7 & 12.1 \\
\hline
\end{tabular}

Source: The American College Testing Program (2003). 
The largest study of persistence and dropout rates undertaken in the UK involved more than 500 college staff, 8,500 students, and 33 colleges [14]. This study confirms that students are more likely to dropout if they:

- Do not feel they have been placed in the most appropriate course

- Applied to college late

- Find it difficult to make friends

- Find it difficult to settle in at the beginning of their course

- Are less satisfied than current students with the quality of teaching

- Are less satisfied than current students with their course timetable

- Are less satisfied than current students with help either to get a job or to go to university

- Are male

- Have difficult financial circumstances (older students) or family circumstances (younger students).

- Have their fees waived or reduced

A study of external students enrolled in the fourth year of the Bachelor of Education program at Edith Cowan University [15] examined demographic, academic, and administrative variables to determine the extent to which these variables were related to attrition and persistence. The students reported that work, family, study commitments, insufficient time, ill health, and study load were reasons why they withdrew from the program. Gender and geographic location of the student were not found to be significant predictors of attrition between continuing and withdrawn students. The relationship between the student and the instructor, in terms of the students' satisfaction with their communication with the teacher, is one of the factors that distinguish students who choose to continue or dropout. Along these lines, a recent review of dropouts in web-based distance education concluded that communication or social interaction between students and between the teacher and the students represent a major factor in the decision to withdraw from a web-based course [16].

$\mathrm{Li}$ and Killian [17] examined patterns of attrition at a Midwestern research university and found that students' financial status is an important factor in persistence in higher education. Li and Killian's results also revealed a variety of reasons why students leave college, and that they usually had more than one reason for leaving. The most often endorsed reasons for leaving were grouped as academic factors, personal factors, and financial factors. The financial factor is of special concern when considering online programs, because these programs usually lack federal financial aid despite the recent moves toward the amendment of current regulation [18].

Interviews with students of a distance master's program offered at Boise State University were conducted to determine why students drop out of a program. The students who dropped out of the distance program, as well as those who continued in the program between 1989 and 1996, were interviewed. The main factor that influenced their decision to continue or to drop out of the program was their level of satisfaction with the first or second course in the program. Specific reasons for dropping out included dissatisfaction with the learning environment, discrepancies between professional or personal interests and the course structure, low confidence levels in distance learning, doubts about successful online communication, incompetence in using the distance education software as an effective learning tool, feeling overwhelmed by the advanced knowledge and information overload, and the de-personalized learning environment [19]. 
While the above studies are examples of the considerable investigation that has focused on the dropout problem in traditional distance education [15], there has been very little research on dropouts in online education. Frankola [21] says that there are "no national statistics, but a recent report in the Chronicle for Higher Education found that institutions report dropout rates ranging from 20 to 50 percent for distance learners.” O’Connor, Sceiford, Wang, Foucar-Szocki, and Griffin [22] claimed that the dropout rate for elearning is approximately 26 percent after surveying e-learners and e-learning managers from various organizations and industries. Giles affirms that "very little is known about the reasons for dropout or completion in online, computer-conferenced classes, probably because offering courses totally online is a relatively new concept" [20]. She adds "To date, no one has researched and published online student persistence rates and reasons for dropout in computer-conferenced classes, most probably because the computer-conferencing format is so new" [20]. In addition, information about dropout rate in online programs is often anecdotal and vague.

Carr [23] says that almost every distance-education instructor and student has a different explanation for why students drop out of online courses. Nevertheless, all these explanations can be separated into two camps:

(a) belief that students dropout of distance courses for essentially the same reasons they dropout of traditional courses, and

(b) belief that the reasons for dropping out are connected to the fundamental differences between the two modes of instruction.

In summary, research has shown that the reasons for dropping out of a distance education course or program are complex, multiple, and inter-related. By gaining insights into the reasons why students dropout of online programs, institutions that provide such programs can begin to develop strategies to decrease attrition and maintain enrollment rates in their programs.

\section{RESEARCH QUESTIONS AND DESIGN}

The purpose of this study was to determine why students drop out of an online program. In particular, this study focused exclusively on an online master's degree program offered by the Department of Human Resource Education (HRE) at the University of Illinois at Urbana-Champaign. This program, called HRE Online, awards a master's degree upon completion of 9 graduate courses. The specific questions addressed in this study included:

Why did students dropout of the online program?

When did they dropout in the online program?

Are there factors that can predict the likelihood of a student dropping out of an online program?

Dropout rates in online programs are known to be significant. The cost of losing a student is very high in terms of wasted time, effort, and money on the part of the student, the faculty, and the institution. As soon as an online student leaves the program, almost all connection with this student is lost, and institutions usually do nothing to determine why the student left. By knowing the reasons that lead a student to leave an online program, institutions can implement strategies to anticipate and reduce the number of program dropouts. Although online programs are growing and enrolling more students than ever before, at this time there is a lack of research focused on persistence and attrition in those programs. The present study helps build a foundation for future research in this area. 


\section{A. Method}

This study utilized an electronic survey method to investigate the research questions. The electronic approach allowed data to be collected at low cost and relatively low response burden on the part of the participants. This was important for two reasons. First, the relatively high mobility of the dropout population was a big constraint, especially when trying to contact dropout students who left the program more than a year ago. Second, because the potential participants had made a decision to leave the educational program, they were unlikely to feel an allegiance to the program and may be more likely to refuse to respond.

\section{B. Participants}

Students who dropped out of the HRE Online master's degree program at the University of Illinois at Urbana-Champaign were the focus of this study. Students were admitted to the HRE Online degree program in cohorts of approximately 30 students. Data were collected from the first three cohorts of students. Each cohort of students started the program as a group and enrolled in the same sequence of courses throughout the three-year program of study. The first and second cohorts had completed the program and the third cohort was over half way through the program.

The participants in this study were defined as those students who dropped out of the degree program after starting their first course. A total of 83 students were accepted into the online program and started the first course. At the time of the study, 28 of these students had left the program. The overall dropout rate for the HRE Online program was 34\%. The cohort with the highest dropout rate was HRE \#2, with 44\%, followed by HRE \#1 and HRE \#3, with $27 \%$ and $26 \%$ respectively. A summary of the enrollment dropout data for each cohort is shown in Table 2 and a comparison of demographic data for program persisters and dropouts is shown in Table 3.

Table 2: Summary of Enrollments and Dropouts

\begin{tabular}{lllll}
\hline Students & Cohort \#1 & Cohort \#2 & Cohort \#3 & Total \\
\hline Started First Course & 22 & 34 & 27 & 83 \\
Left Program & 6 & 15 & 7 & 28 \\
Dropout Percentage & $27.3 \%$ & $44.1 \%$ & $25.9 \%$ & $33.7 \%$
\end{tabular}

Table 3: Comparison of Persisters and Dropouts for HRE Online

\begin{tabular}{lllll}
\hline & Persisters & Dropouts & Total & Dropout \% \\
\hline Gender & & & & \\
\multicolumn{1}{c}{ Male } & $16(29.1 \%)$ & $12(42.9 \%)$ & $28(33.7 \%)$ & $42.9 \%$ \\
\multicolumn{1}{c}{ Female } & $39(70.9 \%)$ & $16(57.1 \%)$ & $55(66.3 \%)$ & $29.1 \%$ \\
\hline Average Age (SD) & $41(9.10)$ & $42(9.28)$ & $42(9.09)$ & \\
\hline Ethnicity & & & \\
White & $45(81.8 \%)$ & $19(67.9 \%)$ & 64 & $29.7 \%$ \\
Black & $9(16.4 \%)$ & $4(14.3 \%)$ & 13 & $30.8 \%$ \\
Hispanic & $0(0 \%)$ & $1(3.6 \%)$ & 1 & $100 \%$ \\
Asian/Pacific Islander & $1(1.8 \%)$ & $3(10.7 \%)$ & 4 & $75 \%$ \\
American Indian & $0(0 \%)$ & $1(3.6 \%)$ & 1 & $100 \%$ \\
\hline Average GPA (SD) & $3.16(.428)$ & $3.34(.495)$ & $3.22(.460)$ & \\
\hline
\end{tabular}




\begin{tabular}{cllll}
\hline Location & & & \\
Illinois Resident & $38(69.1 \%)$ & $17(60.1 \%)$ & 55 & $30.9 \%$ \\
Non-Illinois Resident (U.S.) & $16(29.1 \%)$ & $9(32.1 \%)$ & 25 & $36.0 \%$ \\
International & $1(1.8 \%)$ & $2(7.1 \%)$ & 3 & $66.7 \%$ \\
\hline Occupation & $14(25.5 \%)$ & $7(25.0 \%)$ & 21 & $33.3 \%$ \\
Trainer/Instructor & $23(41.8 \%)$ & $8(28.6 \%)$ & 31 & $25.8 \%$ \\
Director/Manager & $6(10.9 \%)$ & $5(17.9 \%)$ & 11 & $45.5 \%$ \\
HR/OD Consultant & $8(14.5 \%)$ & $6(21.4 \%)$ & 14 & $42.9 \%$ \\
Administrator/Technician & $4(7.3 \%)$ & $2(7.1 \%)$ & 6 & $33.3 \%$ \\
Other & & & &
\end{tabular}

\section{Online Program Description}

The University of Illinois offers an online master's degree in Global Human Resource Development (HRD), an innovative instructional program that uses the Internet and a variety of web-based technologies to provide a collaborative learning environment. The program is taught entirely online, and students are not required to ever visit campus in person. The program was designed to provide both individual and group interaction with the instructor and places a strong emphasis on self-directed learning and virtual teams. The nine-course sequence is designed for individuals currently working in, or aspiring to, HRD positions in either the private or public sector. Course topics focus on employee training and development, organization development, and the use of information and technology to improve individual and organizational performance. Emphasis is placed on HRD leadership in both domestic and international settings. A Master's of Education (Ed. M.) degree is awarded upon completion of the program.

Students begin the program in a cohort of approximately thirty students. They complete one twelve-week course each semester over a three-year period. Each online course is divided into modules that serve as the organizing structure for the course. On average, one module is covered each week. Each module begins with an overview of the topic followed by an assignment related to the application of the content. Course content is delivered through pre-recorded streamed audio lectures, PowerPoint presentations that are synchronized with the streamed lecture, online readings, and traditional textbooks. After the students have reviewed the content in a module, they typically complete one or more "application" assignments. These application assignments require the students to apply what they have learned by posting information on a discussion board, interacting with the instructor and students in chat sessions, and completing course projects. About half of the assignments require students to work with their "virtual team" to complete group assignments. At the start of each class, the students are assigned to a virtual team of 4 to 5 members and they interact using various communication technologies.

The Internet-based technologies used in the online program were specifically selected to support communication and collaboration of the virtual teams. The online course supported the direct use of email, a collaborative web forum (WebBoard ${ }^{\mathrm{TM}}$ ), synchronous text chat, and Internet pagers (e.g., Instant Messenger $\left.{ }^{\mathrm{TM}}\right)$. The instructor facilitates the discussion on WebBoard ${ }^{\mathrm{TM}}$ where the students post questions, issues, comments, and concerns that will help them better understand the topics.

A unique aspect of the online courses is the requirement that all students participate in a weekly synchronous class session. These one-hour synchronous sessions consist of a live streaming audio broadcast from the instructor accompanied by real time text chat among the students. During each live 
session, the students gather virtually in the chat room using mIRC and listen to a live audio broadcast from the instructor. The students use mIRC to ask questions, respond to the instructor's questions, and participate in discussion with the class, since the entire class is in the same chat room. The students also use separate chat rooms for small group work during breakout sessions. The live broadcast and text chat messages are archived for later use by the students.

\section{Instrumentation}

A web site was developed that contained a general explanation of the purpose of the study, a set of questions, and explicit directions for completing the online questionnaire. The questionnaire was developed based on a review of the literature, with particular attention to other questionnaires that examined factors related to attrition. The survey contained the following nine questions: four with openended responses, three with yes-no responses, and two with multiple choice/section responses:

1. Why did you choose to enroll in the HRE Online program?

2. I left because... (Here, a scroll down menu with 23 options was presented)

3. Of the above reasons, please describe your main reason for leaving the HRE Online program

4. During the program, did you feel "information overload"? If YES, please explain the problem you had with information overload

5. Did you have a regular time set aside to work on the courses? If YES, when?

6. Where did you complete most of the assignments while you were enrolled?

7. Why did you do most of your work at that location?

8. Did you get behind in your assignments? And if so, did you receive encouragement from the instructor/teaching assistant to catch up with the class?

9. Please, provide us with comments, suggestions, or thoughts you may have regarding the questions you just answered.

\section{E. Data Collection}

Information was collected primarily from the program dropouts, although additional information was collected from the online coordinator, program director, and the department secretaries. Demographic data for all online program participants (i.e., both those who persisted in the program and those who dropped out) was collected as the first step in the data collection process. Student records were reviewed to obtain e-mail and mailing address, age, gender, ethnic background, cumulative GPA from previous undergraduate and graduate courses, location of residence, and current occupation. These data were entered into a spreadsheet for later analysis. The data were also coded to classify each student as a program persister or dropout.

Attempts were made to contact each of the students who dropped out of the program to solicit their willingness to participate in the survey. Each of the students was sent an e-mail message that informed them of the purpose of the study and displayed a URL where the questionnaire was located. They were asked to complete the questionnaire and submit the answers electronically. If an e-mail address did not work (e.g., message was bounced back), a letter was sent to the student using their most recent mailing address. Based on the initial low response rate, it was determined that much of the contact information provided by the university was out-of-date.

Attempts were then made to contact those students who had not responded by phone in order to confirm their e-mail and mailing address. Attempts were also made to verify the students' phone numbers and 
addresses using online phone guides and search tools such as Switchboard's Yellow Pages or Yahoo's People Search. Once an updated list of contact information was obtained, the students who had not responded were sent another e-mail message about the study. Two follow-up e-mail messages were sent to the non-respondents with an interval of one week between them. Two letters were also mailed to the non-respondents; the second one contained a reminder and the survey URL and was sent two weeks after the first letter. Telephone calls were also made to contact the students who did not respond to the e-mail request. These participants were given the option to answer the survey by phone. Once contact was made with a student and they were asked to complete the survey, they were not contacted again.

\section{RESULTS}

\section{A. When Online Students Dropout}

Figure 1 summarizes the data showing the number of courses completed by students in each cohort before they dropped out of the program. The data show that students are most likely to leave an online program after completing the first few courses. Few students decide to leave the online program after they have completed several courses. This is to be expected for several reasons. First, the students who persist in the early stages of the program could be viewed as successful students who are possibly satisfied with their learning experience in the program. Second, students who have trouble adapting to the online experience or to the technology are likely to become frustrated in their first few courses. Third, students who have completed several courses in a program would be less likely to give up on their pursuit of the degree after making a significant time and effort investment in the program.

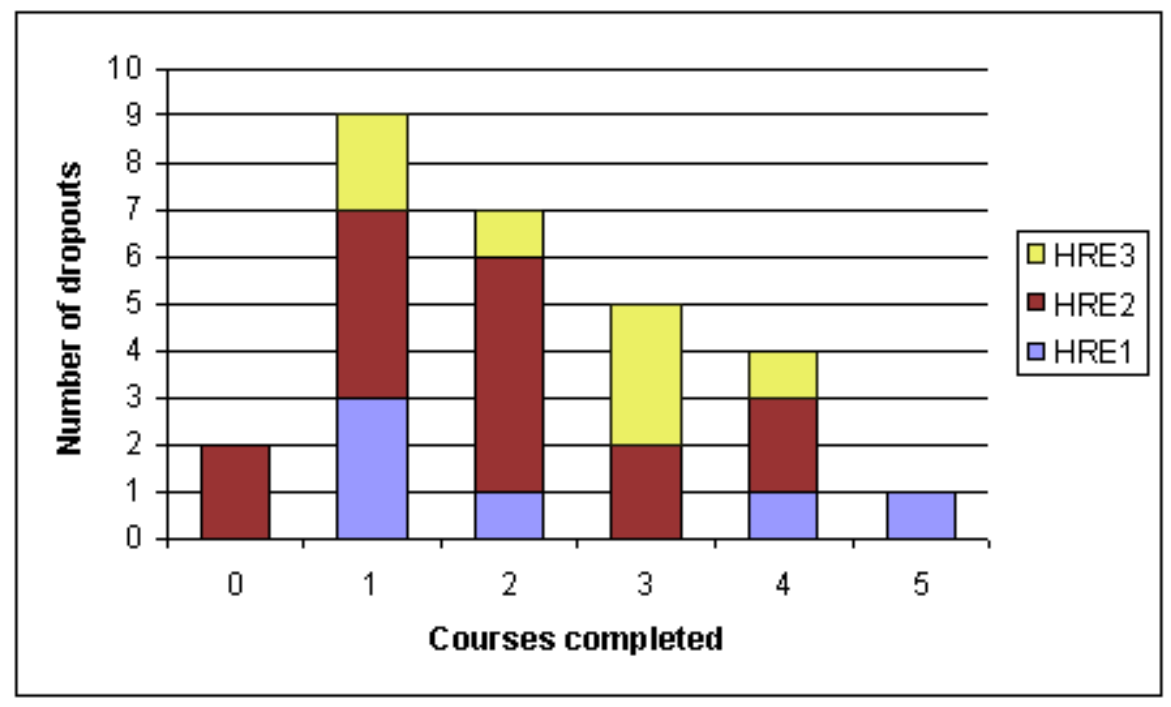

Figure 1: When do they dropout?

\section{B. Logistic Regression Analysis}

A logistic regression analysis was conducted to determine which variables predict persistence/dropout. The Statistical Package for the Social Sciences (SPSS) was used to determine the significance rating of each set of variables. For this study, there were seven independent variables (i.e., age, gender, cohort, ethnicity, occupation, location, and GPA); most of which were categorical variables. 
The first part of the analysis involved the calculation of Pearson correlations to check for independence among the demographic variables. As shown in Table 4, even though significant correlations were found, the relationships between the variables were not highly correlated. Therefore, all variables were sufficiently interdependent to be used in the logistic regression analysis. The results for the logistic regression using all the variables are shown in Table 5 and Table 6 shows the Classification Table that indicates that the model fails to predict instances of dropouts (39\%).

Table 4: Pearson Correlation Results

\begin{tabular}{lcccccccc}
\hline & Cohort & Gender & Age & GPA & Ethnicity & Location & Occupation & $Y$ \\
\hline Cohort & 1 & -.180 & -.057 & .162 & .0536 & .260 & $.291^{*}$ & -.024 \\
Gender & -.180 & 1 & -.015 & -.082 & -.230 & $-.364^{*}$ & -.045 & -.152 \\
Age & -.057 & -.015 & 1 & .116 & $-.314^{*}$ & -.180 & -.200 & .027 \\
GPA & .162 & -.082 & .116 & 1 & -.011 & .169 & .005 & .185 \\
Ethnicity & .0536 & -.230 & $-.314^{*}$ & -.011 & 1 & .258 & .185 & $.288^{*}$ \\
Location & .260 & $-.364^{*}$ & -.180 & .169 & .258 & 1 & .131 & .112 \\
Occupation & $.291^{*}$ & -.045 & -.200 & .005 & .185 & .131 & 1 & .077 \\
Y & -.024 & -.152 & .027 & .185 & $.288^{*}$ & .112 & .077 & 1 \\
\hline
\end{tabular}

* Correlation is significant at the 0.01 level (2-tailed).

Table 5: Logistic Regression Results

\begin{tabular}{lcccc}
\hline Variable & B & S.E. & $d f$ & Sig. \\
\hline Gender & .655 & .633 & 1 & .301 \\
Age & .036 & .033 & 1 & .272 \\
GPA & .990 & .647 & 1 & .126 \\
Ethnicity & & & & \\
$\quad$ White & -7.963 & 36.676 & 1 & .828 \\
$\quad$ Black & -7.914 & 36.678 & 1 & .829 \\
$\quad$ Hispanic & -7.598 & 36.703 & 1 & .836 \\
$\quad$ Asian & 1.428 & 51.859 & 1 & .978 \\
$\quad$ American Indian & .628 & 51.859 & 1 & .990 \\
Location & .162 & .668 & 1 & .808 \\
Occupation & & & & .716 \\
$\quad$ Trainer/Instructor & -.400 & 1.097 & 1 & .798 \\
$\quad$ Director/Manager & -.265 & 1.038 & 1 & .505 \\
$\quad$ HRD/OD Consultant & .828 & 1.242 & 1 & .849 \\
$\quad$ Administrator/Technician & .220 & 1.157 & 1 & .567 \\
Cohort (1) & .466 & .814 & 1 & .112 \\
Cohort (2) & 1.020 & .642 & 1 & \\
\hline
\end{tabular}


Table 6: Classification Table (cut value was .50)

\begin{tabular}{|c|c|c|c|c|}
\hline \multirow{3}{*}{\multicolumn{2}{|c|}{ Observed }} & \multicolumn{3}{|c|}{ Predicted } \\
\hline & & \multicolumn{2}{|c|}{$Y$} & \multirow{2}{*}{$\begin{array}{c}\text { Percentage } \\
\text { Correct }\end{array}$} \\
\hline & & .00 & 1.00 & \\
\hline \multirow[t]{2}{*}{$Y$} & .00 & 48 & 6 & 88.9 \\
\hline & 1.00 & 17 & 11 & 39.3 \\
\hline \multicolumn{3}{|c|}{ Overall Percentage } & & 72.0 \\
\hline
\end{tabular}

\section{Survey Results}

The online survey was used to collect specific information from the dropout students regarding their experience in the online program. The goals of this survey were to supplement the quantitative analysis of the demographic variables and to identify patterns that might reveal the factors that influence the decision to leave an online program. Ten of the 28 students who left the program completed the online survey (36\%). This response rate highlights the difficulty in contacting and gathering information from students who have left an academic program. The results of their responses are summarized below.

\section{Reasons for Enrolling in an Online Program}

Students enrolled in the HRE Online program because of the flexibility of schedule, the convenience and effectiveness of taking online classes, the good fit with their goals, for professional development, to obtain an advanced degree in the field, and also because of the strong reputation of the University of Illinois.

\section{Reasons for Leaving an Online Program}

Students reported leaving the online program for a variety of reasons. There did not appear to be a dominant reason for dropping out of the program. Their reasons for leaving the program were organized into personal, job-related, and program-related reasons:

\section{a. Personal Reasons}

Financial difficulties or the long-term financial investment not worth the benefit

Lack of time to complete the assignments, which took more time compared to traditional courses

Schedule conflicts

Family problems

\section{b. Job-related Reasons}

Job responsibilities changed during the program

Their company didn't support the program

Too hard to work full-time and be a student in an online course

\section{c. Program-related Reasons}

Too many low level assignments 
Too difficult working on the group assignments

Lack of one-to-one interaction with the instructors and students

The academic program was too difficult/demanding

Lack of interest in the material or the program didn't meet expectations

\section{d. Technology-related Reasons}

The learning environment was too de-personalized

Not enough support from the technical staff

The technology overwhelmed the content

Lack of technical preparation for the program

The students were then asked to provide the single main reason why they left the online program. The most common responses were that it was too hard to work full-time and be a graduate student (3 responses), the program was no longer applicable to them because of a change in job responsibilities (3 responses), and technology problems or limitations (2 responses). Other reasons included the program was too demanding (in terms of hours needed to complete the assignments) (2 responses), lack of interaction with students and instructors (1 responses), family problems (1 responses), and the chat room discussions were not meaningful (1 responses). (Note: Some students provided two instead of one main reason for dropping out).

\section{Study Habits of Online Students Who Dropout}

The dropout students were asked a few questions about their study habits while enrolled in the online program.

\section{a. Study Times and Locations}

Six of the dropout students had a regular time set aside to do their course work while four reported that they did not have a work schedule. The most common times to work were weekends (2), every evening (2), selected evenings and flexible weekend hours (1), a few hours each night plus any time that could be "squeezed" in at work (1). Nine of the students who dropped out completed their course work at home and one completed assignments at work.

The reasons provided for working at home were primarily because of convenience and privacy. They reported having fewer interruptions at home, which allowed them to better concentrate there. The home is also more comfortable, allows convenient access to their course materials (e.g., texts, computers, etc.), and it is where they had time to spend on their assignments. The students mentioned that they were not allowed to do school work at their place of employment. They also mentioned that it was difficult to work in hotels because of slow Internet connections.

\section{b. Assignment Scheduling}

About half of the students who dropped out (4) reported falling behind on their assignments while the other half (6) was able to keep up with their schoolwork. Overall, the dropouts found the professors and the online staff to be helpful, understanding, and encouraging. 


\section{c. Information Overload}

Three of the dropout students reported that information overload was a problem for them. They reported that there was too much reading (2), too many modules, and a lot of information per module (1). Seven of the students reported that information overload was not a problem for them.

\section{SUMMARY AND CONCLUSIONS}

Because the focus of this study was on a single program with a small number of dropout students, the generalizability of the results of this study is greatly limited. However, the following summary of the findings provides a baseline for future quantitative analyses of factors that influence students' decisions to leave an online program.

Based on the findings of this study, several tendencies affecting dropout rates were identified. First, the data show that males are more likely to drop out than females; however, no explanation for this finding emerged in this study. Second, age does not appear to be a factor in the decision to drop out of an online program. Third, minorities other than black students are more likely to drop out than white students while white and black students have about the same dropout rate. Fourth, dropouts tend to have a higher GPA average than those who chose to persist in the program. Fifth, the students who were least likely to dropout were employed as directors, managers, and coordinators. Sixth, the only significant variable identified by the logistic regression analysis that might predict likelihood of dropping out was GPA, but the analysis of the Classification Table for this variable indicates that GPA is not a strong predictor. The international students in this study were likely to drop out, and there was no difference in the dropout rate of in-state and out-of-state students, but the sample is too small to generalize.

The reasons given by the online students for dropping out of the program were not very different from those typically given by dropouts from traditional face-to-face programs. Although specific reasons such as technology issues, the lack of human interaction, and communication problems are clearly unique to the online learning environment, there was no evidence to suggest that they were the primary reasons the online students left the program. For the dropout students, the much proclaimed adage of "learning anytime, anywhere” does not seem to apply.

This research confirms that the decision to persist or dropout from an online program is a complex phenomenon that cannot be easily described with quantitative variables, at least not with the demographic variables selected for analysis in this study. Students tend to dropout after completing only a few of the courses in a program. In this study, the highest number of dropouts left after completing the first course.

This study also revealed that tracking dropout students is a very difficult task. There was no systematic procedure in place to locate and contact the dropouts. Information about the registration status of the online students is not as easily available as a stroke of the keyboard. Keeping updated information on students and their registration status could help to red flag possible dropouts, take steps to avoid it, or if that's not possible, gather information about the reasons for leaving. Having a survey ready to complete by recent dropouts can help to get valuable data that can be used to improve retention.

Caution needs to be taken when generalizing the results of this study. Each online program is unique and the reasons given for leaving a program may be specific to the nature and uniqueness of the program. Further, the reasons given by the students for leaving the program may be masked, due to personal issues, by an attempt to place the burden of their leaving on external factors beyond their control. Analysis of the 
perceptions and experiences of the instructors regarding the reasons their students left the program could help to create a more complete description of the dropout phenomenon. It would also be beneficial to include a survey of the persisters' reasons for staying in the program. The contrast between dropouts and persisters could provide further insight into the dropout problem.

\section{REFERENCES}

1. Lockee, B. B., Burton, J. K., \& Cross, L. H. No comparison: Distance education finds a new use for 'No Significant Difference.' Educational Technology Research and Development 47(3): 33-42, 1999.

2. Phipps, R., and Merisotis, J. What's the difference? A review of contemporary research on the effectiveness of distance learning in higher education. Paper prepared for the American Federation of Teachers and the National Education Association. Washington, DC: The Institute for Higher Education Policy, 1999.

3. Gabrielle, D. M. Distance learning: An examination of perceived effectiveness and student satisfaction in higher education. In Proceedings of SITE 2001, Orlando, FL: AACE, 183-188, 2001.

4. Hiltz, S. R. Impacts of college-level courses via asynchronous learning networks: Some preliminary results. Journal of Asynchronous Learning Networks 1(2): 1-19, 1997.

5. Allen, I., E., and Seaman, J. Sizing the Opportunity: The Quality and Extent of Online Education in the Unites States, 2002 and 2003. Needham, MA: Sloan-C, 2003.

6. Ad Hoc Panel on Graduate Attrition Advisory Committee. Office of Scientific and Engineering Personnel. National Research Council. The Path to the Ph.D.: Measuring graduate attrition in the Sciences and Humanities, Washington, DC: National Academy Press, 1996.

7. Guri-Rosenblit, S. Distance and Campus Universities: Tensions and Interactions. A comparative study of five countries. Amsterdam, Netherlands: IUA Press Pergamon, 1999.

8. Dutton, J., Dutton, M., and Perry, J. Do online students perform as well as lecture students? Journal of Engineering Education 90(1): 131-139, 1999.

9. Terry, N. Assessing enrollment and attrition rates for the online MBA. T.H.E. Journal 28(7): 64-68, 2001.

10. Tinto, V. Leaving College: Rethinking the Causes and Cures of Student Attrition. Chicago, IL: The University of Chicago Press, 1987.

11. Bean, J. P. Why students leave: Insights from research. In D. Hossler, J. P. Bean, \& Associates. The Strategic Management of College Enrollments, 170-185. San Francisco, CA: Jossey-Bass, 1990.

12. Cabrera, A. F., Castañeda, M. B., Nora, A., and Hengstler, D. The convergence between two theories of college persistence. Journal of Higher Education 63(2): 143-164, 1992.

13. American College Testing Program. Data compiled from the ACT Institutional Data File for 2003, Iowa City, IA: American College Testing Program, Inc., 2003.

14. Martinez, P., and Munday, F. 9000 voices: Student persistence and dropout in further education. (FEDA Report Vol. 2 No 7). London, UK: Further Education Development Agency. (ERIC Document Reproduction Service No ED 427169), 1998.

15. Thompson, E. Distance education drop-out: What can we do? In R. Pospisil \& L. Willcoxson (Eds.), Learning Through Teaching, 324-332. Proceedings of the $6^{\text {th }}$ Annual Teaching Learning Forum, Perth, Australia: Murdoch University, 1997.

16. Astleitner, H. Dropout and distance education. A review of motivational and emotional strategies to reduce dropout in web-based distance education, October 13, 2000. Online. Available: http://daisy.fmi.uni-passau.de//lebre/ss99/ringvorlesung/material/astleitnerabstract.html.

17. Li, G., and Killian, T. Students who left college: An examination of their characteristics and reasons for leaving. AIR Forum Papers, (ERIC ED 433 779), 1999.

18. Golden, D. The Wall Street Journal, Jan. 31, 2001.

19. Chyung, Y., Winiecki, D., \& Fenner, J. A. Evaluation of effective interventions to solve the dropout problem in adult distance education. Proceedings of EdMedia 1999, 51-55. Seattle, WA, 1999. 
20. Giles, I. M. An examination of persistence and dropout in the online computer-conferenced classroom. Doctoral dissertation, Virginia Polytechnic Institute and State University, 1999.

21. Frankola, K. Why online learners dropout. Workforce 10: 53-63, 2001.

22. O’Connor, C., Sceiford, E., Wang, G., Foucar-Szocki, D., and Griffin, O. Departure, abandonment, and dropout of e-learning: Dilemma and solutions. March 30, 2004. Online. Available: http://www.masie.com/researchgrants/2003/JMU_Final_Report.pdf.

23. Carr, S. As distance education comes to age, the challenge is keeping the students. The Chronicle of Higher Education, February 11, 2000.

\section{ABOUT THE AUTHORS}

Pedro A. Willging is a graduate research assistant at the University of Illinois at Urbana-Champaign where he is working on his $\mathrm{Ph}$. D. in online instruction. He is also a professor at the University of La Pampa (Argentina) where he is teaching an online undergraduate course.

Scott D. Johnson is a professor and head of human resource education at the University of Illinois at Urbana-Champaign. Dr. Johnson specializes in instructional design, instructional methods, and online learning. 

